\title{
A simplest method to avoid inflammation and infection after the insertion of a piercing (even using the safest metal), by using quaternium-15
}

\section{Lorenzo Martini ${ }^{1}$, Piotr Brzezinski ${ }^{2}$}

${ }^{1}$ University of Siena, Department of Pharmaceutical Biotechnologies, Via A. Moro 2, 53100 Siena, Italy, ${ }^{2}$ Institute of Biology and Environmental Protection, Pomeranian Academy, Slupsk, Poland

Corresponding author: Lorenzo Martini, E-mail: martinil163@libero.it

\begin{abstract}
Background: The novel fashion of youngest boyd and girls to insert piercings even in the most hiddenparts of the body (heritage of troglodytes and cavernicolous persons) cause always infections and our attention is focused on a novel practice to defeat this typology of infection, avoiding to use generical over the counter creams that are perilous and do not solve the problem. Material and Methods: A 19 years old girl after a piercing in her nostril with brownish discharge from her nose and felt nausea. Results: Was used $0.2 \%$ solution of quaternium-15 in white rubbing ethanol, instead low dosages of triclosan. The duration of the tratment lasted 10 days and the quantity of brown mucus decreases day after day from the infected nostril of the volunteer. Conclusions: Till 2016 even in the US triclosan was considered the best remedy to combact infections caused by metal insertions in skin:now even in Europe its use has been restricted to $0.3 \%$, although this percentage is completely unuseful to treat all microbiota that can invade skin injured by the insertion of a metal. The usage of an ethanolic solution of quaternium-15 is very efficient.
\end{abstract}

Key words: Piercings; Staphylococcus epidermidis; Corynebacterium; Propionibacterium; triclosan; Quaternium-15

\section{INTRODUCTION}

When a piercing is new, it's normal to see some swelling, redness, or discoloration around the site. Some clear discharge that dries and forms a crystal-like crust around the piercing. These symptoms should get better over time, not worse.

Two of the most common complications are allergic reactionsand bacterial infections. Allergic reactions happen if you're allergic to the type of metal being used. For example, piercing jewelry made of nickel is known to cause allergic reactions in susceptible people [1].

Metals that are safe for body piercings include:

- surgical steel

- solid 14-karat or 18-karat gold
- niobium

- titanium

- platinum

Bacterial infections arise when bacteria from dirt or foreign objects get into the open piercing while it's still healing. Remember, piercings are open wounds that need to be kept clean.

Signs of an allergic reaction include:

- development of an itchy, inflamed rash around the piercing that spreads to a larger area

- a pierced hole that looks larger than before

- tenderness that may come and go

Signs of infection include:

- severe swelling with pain and redness

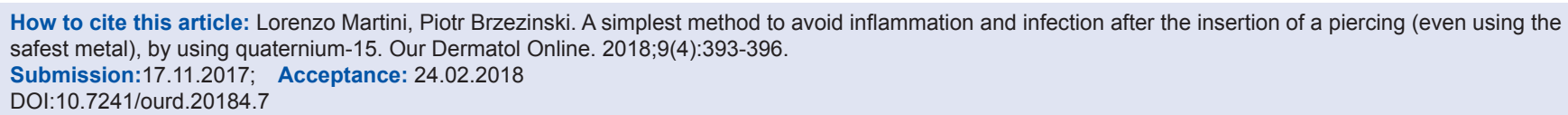


- yellow, green, gray, or brown discharge that has an odor

- red lines that radiate from the piercing site

- fever, chills, dizziness, upset stomach, or vomiting

If there is a suspect of an infection, don't remove the jewelry on your own, unless your doctor tells you to do so. Most piercings don't need to be removed to treat infections. Keeping the piercing hole open allows pus to drain. Allowing the hole to close may trap the infection inside of your body, causing an abscess to form $[1,2]$.

Microorganisms colonizing the skin have long been of interest to dermatologists and microbiologists [3]; our knowledge of these microorganisms has, until recently, been gleaned through culture-based studies. Historically, Staphylococcus epidermidis and other coagulase-negative staphylococci have been regarded as the primary bacterial colonizers of the skin. Other microorganisms that are generally regarded as skin colonizers include coryneforms of the phylum Actinobacteria (the genera Corynebacterium, Propionibacterium and Brevibacterium) and the genus Micrococcus. Gram-negative bacteria, with the exception of some Acinetobacter spp., are generally not isolated from the skin, but are thought to arise in cultures owing to contamination from the gastrointestinal tract $[4,5]$.

Non-bacterial microorganisms have also been isolated from the skin. The most commonly isolated fungal species are Malassezia spp., which are especially prevalent in sebaceous areas. The Demodex mites (such as Demodex folliculorum and Demodex brevis), which are microscopic arthropods, are also regarded as part of the normal skin flora. Demodexmites feed on sebum and are more prevalent following puberty, preferring to colonize sebaceous areas of the face ${ }^{3}$. Demodex mites may also feed on epithelial cells lining the pilosebaceous unit, or even on other organisms (such as Propionibacterium acnes) that inhabit the same space. The role of commensal viruses has not been studied, and investigations are limited by the available molecular and microbiological means to identify and characterize viruses.

Cleaning the piercing is important, both to prevent and treat an infection. Experts recommend cleaning a piercing no more than twice each day. Some physicians suggest to use a saltwater mixture ( $1 / 2$ teaspoon sea salt per 1 cup of water) to help remove any dried healing secretions followed by a gentle, mild antibacterial soap and water cleansing. No alcohol nor hydrogen peroxide should be employed, as these can dry out skin and irritate the area around the piercing.

It is mandatory to wash hands with an antibacterial soap. Then it is useful to use a cotton swab and the cleaning solution to gently wipe the area around belly button and the ring, nose or mouth or whichever part of the body.

Afterwards it is advisable to pat the area dry with a clean towel.

It i salso advisable to place a warm compress on the infected piercing. This can help the pus drain and cause the swelling to go down. Wet a compress, such as a warm washcloth, with the cleaning solution. Place the compress on the piercing. Gently dry the area with a clean towel after using the wet cloth.

Using an antibacterial cream - not an ointment often clears up minor infections. Ointments are greasy and may block oxygen from getting to the wound, complicating the healing process.

Over-the-counter antibacterial cream exist too, but there is a risk for allergic irritation of the skin with this type of product. If you don't have an allergy with over-the-counter antibiotic cream, you can carefully clean the piercing site, and then follow the directions on the container.

Triclosan (restriction of use in cosmetics $0.3 \%$, according to L.11.10.86 n 713 A V S1 P2 n 28 DM 24.1.87 $\mathrm{n} 91$ ) could be the best solution, even if in case of infections caused by metals $0.3 \%$ of triclosan is unuseful.

Nowaday tricolosan effectively it is retrieved in most cosmetics even dentifrices and shampoos, even if $0.3 \%$ is a percentage excessively poor to disinfect infections caused by piercings.

Moreover some researchers of the Korea University showed the claimed antibacterial activity of triclosan onto 20 bacterial streamsis not appropriate, since its action begins after the sample toilette before to eat with naked hands (like Asians do).

In Europe the SSC (Scientific Steering Committee of CE) in 2002 [6] had declared that che triclosan is an useful ed biocide, confirming that has been used for 
Table I: Quantities of brown mucus excreted by the nostril

\begin{tabular}{|c|c|c|c|c|c|c|c|c|c|c|}
\hline $\begin{array}{l}\text { At the beginning of } \\
\text { the experiment }\end{array}$ & $\begin{array}{l}\text { At } 1^{\text {st }} \\
\text { day }\end{array}$ & $\begin{array}{l}\text { At } 2^{\text {nd }} \\
\text { day }\end{array}$ & $\begin{array}{l}\text { At } 3^{\text {rd }} \\
\text { day }\end{array}$ & $\begin{array}{l}\text { At } 4^{\text {th }} \\
\text { day }\end{array}$ & $\begin{array}{l}\text { At } 5^{\text {th }} \\
\text { day }\end{array}$ & $\begin{array}{l}\text { At } 6^{\text {th }} \\
\text { day }\end{array}$ & $\begin{array}{l}\text { At } 7^{\text {th }} \\
\text { day }\end{array}$ & $\begin{array}{l}\text { At } 8^{\text {th }} \\
\text { day }\end{array}$ & $\begin{array}{l}{\text { At } 9^{\text {th }}} \\
\text { day }\end{array}$ & $\begin{array}{l}\text { At } 10^{\text {th }} \\
\text { day }\end{array}$ \\
\hline 55 & 50 & 46 & 44 & 41 & 39 & 36 & 33 & 21 & 16 & nil \\
\hline
\end{tabular}

35 years all over the world for preserving cosmetics and even for oral mucosae.

The Swedish Ministery of Health has banished it at all in food and cosmetics, since like all the chlorinated phenols can accuulate in all the human tissues and in maternal milk and so alterate the liver function, can cause lung distruption and induce sterility and alterate the immune system till complete paralysis.

Finally since 2016 triclosan has been banned by FDA in US.

Because of all these complications it is better not to employ soaps containing triclosan.

The othe ingredient I have chosen is quaternium 15, (hexamethylenetetramine chloroallyl chloride) that is a quaternary ammonium salt used as a surfactant and preservativein many cosmetics and industrial substances. It is an anti-microbial agent by virtue of being a formaldehyde releaser 4,6] however this can also cause contact dermatitis, a symptom of an allergic reaction, especially in those with sensitive skin.

For the fact that is reputed a formaldehyde releaser can be used at concentration of $0.2 \%$, that is sufficient to guarantee a complete disinfection of the area where piercing must be removed and cleaned day after day.

\section{MATERIALS AND METHODS}

A girl (19 years old) desired to be visited since she showed a continuous brownish discharge from her nose and felt nausea and told to me that she had inserted a piercing (made of surgical steel) one week before, in her nostril.

After the preface, We directly have chosen the quaternium-15, instead low dosages of triclosan.

Quaternium-15 is not water soluble, but is only sluble in ethanol, ether and alkaline concentration.
We had prepared a $0.2 \%$ solution of quaternium- 15 in white rubbing ethanol and We prayed her to remove the piercing twice a day and make all the operations generally physicians suggest.

To consider the results, We obtained We have kept on account only the secretion of the brown discharge, measuring exactly by the aids of an electronic scale.

The duration of the tratment lasted 10 days and We have measured since the very first day the quantity in mg of brown mucus the volunteer excreted day after day.

\section{RESULTS}

In Table I it is possibile to state how the quantity of brown mucus decreases day after day from the infected nostril of the volunteer. Measures are reported in $\mathrm{mg}$.

\section{CONCLUSIONS}

One can notice that during the first 10 days after the application of a metal piercing (that had caused inflamation and infection) the usage of an ethanolic solution of quaternium- 15 is very efficient.

There has been not any necessity to repeat the treatment.

\section{STATEMENT OF HUMAN AND ANIMAL RIGHTS}

All procedures followed were in accordance with the ethical standards of the responsible committee on human experimentation (institutional and national) and with the Helsinki Declaration of 1975, as revised in 2008 .

\section{STATEMENT OF INFORMED CONSENT}

Informed consent was obtained from all patients for being included in the study. 
www.odermatol.com

\section{REFERENCES}

1. Kawshar T, Rajesh J. Sociodemographic factors and their association to prevalence of skin diseases among adolescents. Our Dermatol Online. 2013;4:281-6.

2. Puri N, Puri A. A study on contact dermatitis to hair dye and henna. Our Dermatol Online. 2013;4:545-8.

3. Akrami K, Sweeney DA. The microbiome of the critically ill patient. Curr Opin Crit Care. 2018;24:49-54.

4. Kerr BJ, Trabue SL, van Weelden MB, Andersen DS, Pepple LM. Impact of narasin on manure composition, microbial ecology, and gas emissions from finishing pigs fed either a corn-soybean meal or a corn-soybean meal-dried distillers grains with solubles diets. J
Anim Sci. 2018;96:1317-29.

5. Coman OA, Ungureanu A-M, Coman LI. Atopic dermatitis and skin microbiome - new therapeutic approaches. Rom J Clin Exp Dermatol. 2015;2:17-22.

6. Segre EAG, Segre JA. The skin microbiome. Nat Rev Microbiol. 2011;9:244-53.

Copyright by Lorenzo Martini, et al. This is an open-access article distributed under the terms of the Creative Commons Attribution License, which permits unrestricted use, distribution, and reproduction in any medium, provided the original author and source are credited.

Source of Support: Nil, Conflict of Interest: None declared. 